\title{
Composite sorbent for liquidation of oil pollution
}

\author{
Irina Isaeva $^{1 *}$, Irina Odinokova ${ }^{1}$, Galina Ostaeva ${ }^{1}$, and Ekaterina Eliseeva ${ }^{1}$ \\ ${ }^{1}$ Moscow Automobile and Road Construction State Technical University (MADI), Leningradsky pr. \\ 64, Moscow 125319, Russia
}

\begin{abstract}
A method of effective elimination and localization of oil spills using a composite sorbent has been developed. The resulting material consists of polymer waste, mineral filler and surfactant. Due to the peculiarities of the method, the resulting sorbent allows the utilization of polymer waste and has a high oil capacity. The size of the sorbent can vary depending on the specified parameters, what simplifies storage and application.
\end{abstract}

\section{Introduction}

Various factors have a negative impact on the environment and people. The waste from polymer production, in particular expanded polystyrene and emergencies associated with oil pollution take a special place [1-5]. We have investigated the effect of shouldering and burning of expanded polystyrene separately and as part of mixed waste was investigated by us. The presence of substances of high toxicity was detected.

There are many methods of recycling polymer waste, but the most modern approach involves reuse. Use of polymer waste materials for production of sorbents for the elimination of oil spills is one of the promising method. Materials obtained in this way have a high oil capacity and relatively low costs $[6,7]$.

However, existing sorbents have a number of disadvantages. The strict requirements for storage and use are main disadvantages. The sorbent obtained which we obtained has the form of sheets. The plasticity and strength of the sorbent ensure ease of use and storage. This article focuses on the preparation and properties of the composite sorbent.

\section{Experimental}

Polymer waste - expanded polystyrene $\left[\mathrm{CH}_{2}-\mathrm{CH}\left(\mathrm{C}_{6} \mathrm{H}_{5}\right)\right] \mathrm{n}(1)$, vermiculite (2) and surfactants - $\left.\mathrm{CH}_{3}\left(\mathrm{CH}_{2}\right)_{15} \mathrm{NH}_{2}\right)$ (3) were used as starting components. The composite sorbent was obtained by mixing vermiculite with a polymer waste previously converted to a viscous fluid state at room temperature. At the same time, (1) acted as a binder for the mineral filler. 1,2-dichloroethane $-\mathrm{C}_{2} \mathrm{H}_{4} \mathrm{Cl}_{2}$ (4) was used as a solvent for (1). The calculated amount of surfactant was added. Cross-linked expanded polystyrene (5) was

${ }^{*}$ Corresponding author: irina-razumova-xim@yandex.ru 
used as an additive to improve plastic properties. Meanwhile, mass ratio of $(1) /(2) /(5) /(3)$ 70:2:9:1. The composite sorbent can be prepared during $2-3$ hours, at room temperature in air.

This sorbent was worked out on light oil products The oil capacity of the obtained samples was studied by the gravimetric method by the difference between the final and initial mass.

A comparative analysis of the oil capacity of the composite sorbent and the existing ones at the experimental industrial site of OOO "TEK SOLOVAT" was carried out.

The study of the properties of the sorbents was carried out on a porous surface, at a temperature of $120^{\circ} \mathrm{C}$, at normal humidity. The polluting substance was kerosene.

\section{Results and Discussion}

The composite sorbent is a porous, plastic material. The size of which may vary depending on the operating conditions.

The method of obtaining a composite sorbent allowed us to obtain a well-developed surface. The use of expanded polystyrene as a binder binds them together and does not allow light granules of mineral filler to crumble, which significantly reduces the cost of the product. At the same time, the binder slightly reduces the active surface area of the granules, which can lead to a decrease in sorption properties. That is why it became necessary to use it as a surfactant. Figure 1 depicts the oil capacity curves with and without surfactants.

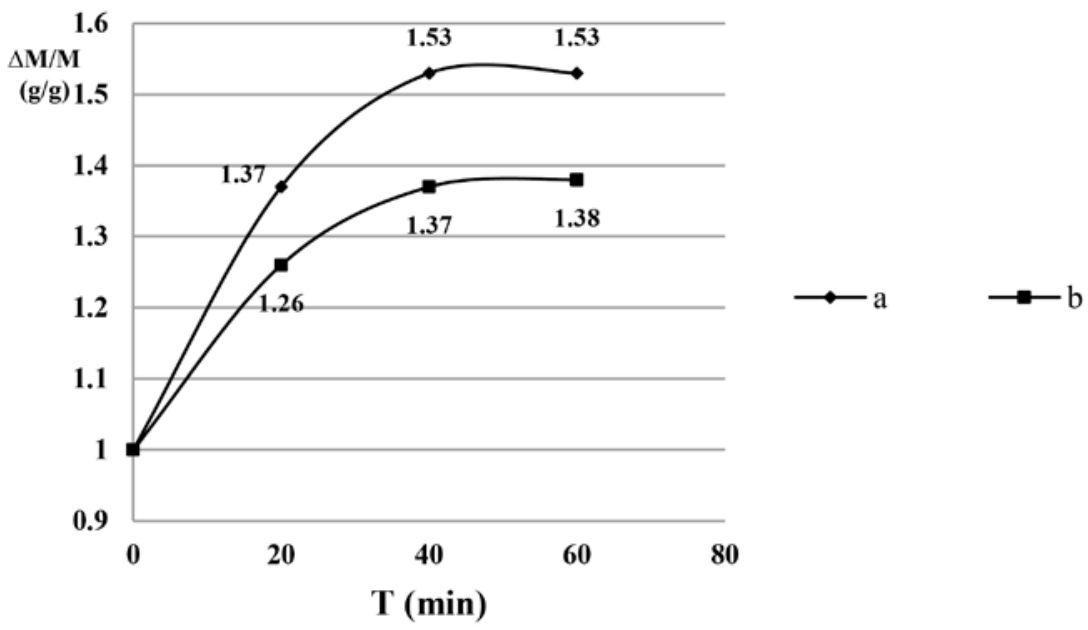

Fig. 1. Oil capacity charts for samples with (a) and without surfactants (b).

It is known that porous surfaces are good at absorbing spills of pollutants. Therefore, when working on the composite sorbent, the time factor was taken into account. Two features are especially important. First, both (a) and (b) profiles are virtually identical for 10 -min that point to effective and fast sorption process. Secondly, a sharp rise in the graph line corresponding to sample (a) indicates a significant influence of surfactants on the sorption process. The presence of surfactants provides a significant increase in sorption for 20 minutes and beyond. This feature does not allow the surface to absorb large amounts of oil products. The increase in plasticity allowed to improve the sorption properties. For this purpose, a cross-linked expanded polystyrene was added to the composition of the composite sorbent. The result is shown in Figure 2. 


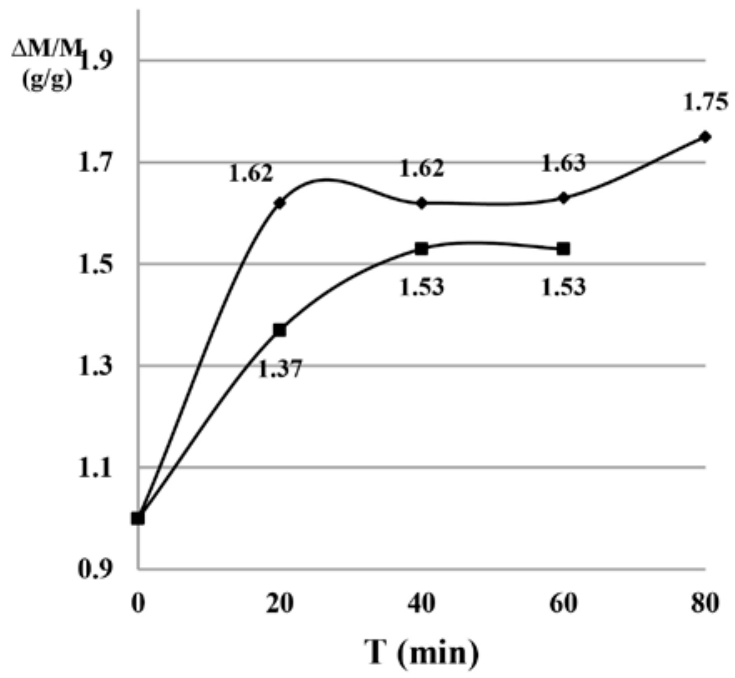

Fig. 2. Oil capacity charts for samples with (a) and without cross-linked expanded polystyrene (b).

The addition of cross-linked expanded polystyrene made it possible to increase the plasticity and contact area of the sorbent with the contaminated surface. This led to an increase in oil capacity by $14 \%$. Figure 3 depicts the oil capacity curves of the resulting composite sorbent and the sorbents used.

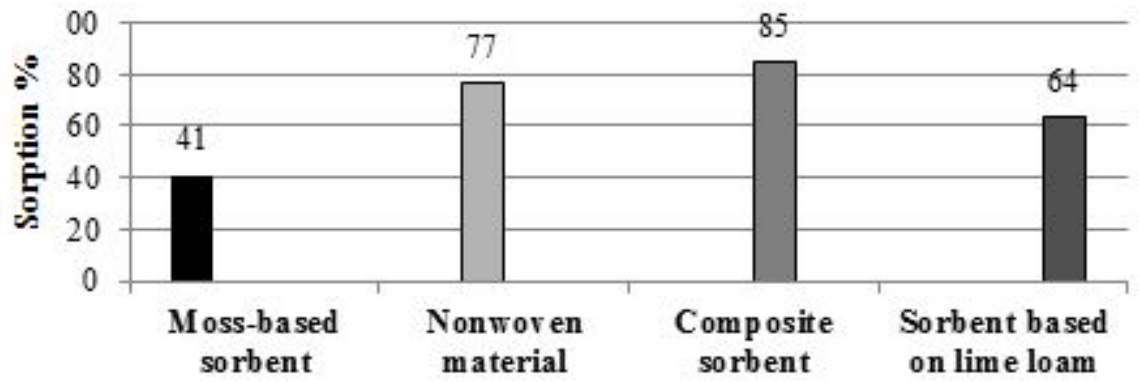

Fig. 3. Oil capacity of sorbents.

The oil capacity of the composite sorbent exceeds the oil capacity of the sorbents used. This is due to its high adhesion to the contaminated surface, which is achieved due to its optimal qualitative and quantitative composition.

\section{Conclusions}

The features of the method of obtaining a composite sorbent make it possible to reuse the polymer waste of expanded polystyrene, what decrease the negative impact on the environment and humans, as well as significantly reduces the cost of the final product. The use of this method allows one to obtain a sorbent of a given, variable size, which facilitates application and storage. The obtained data showed that the composite sorbent has a high oil capacity and the promising potential. 


\section{References}

1. L. Cai, J. Wang, Z. Tan, Z. Zhan, X. Tan, Q.V. Chen, Environ. Sci. Pollut. Res. 24, 24928-24935 (2017)

2. M.T. Garcia, G. Duque, I. Gracia, A. Lucas, J.F. Rodriguez, J. Mater. Cycles and Waste Manag. 11, 2-5 (2009)

3. D.S. Achilias, A.Giannoulis, G.Z. Papageorgiou, Polym. Bull. 63, 449-465 (2009)

4. J.K. Lee, J.H. Shin, Korean J. Chem. Eng. 19, 267-272 (2002)

5. A. F. Tumanyan, N. V. Tyutyuma, A. N. Bondarenko \& N. A. Shcherbakova Chemistry and Technology of Fuels and Oils 53, 369-376 (2017)

6. A.M. Magerramov, A.A. Azizov, R.M. Alosmanov, E.S. Kerimova, I.A. Buniyat-zade, Young Scientist 4, 38-41 (2015)

7. E. C. Kerimova, A. A. Azizov, R. M. Alosmanov, I. A. Bunt-zade, Young Scientist 16, $117-120$ (2017) 